\title{
Too fast to bother? Integrity, Instrumentality, and Externality Factors for Early Sustainable Design Implementation in the Fast-Moving-Consumer-Goods Sector
}

Dr. Curie Park*, Centre for Industrial Sustainability, Institute for Manufacturing, University of Cambridge, 17 Charles Babbage Road, Cambridge, CB3 0FS, UK, cp538@cam.ac.uk

Prof. Fiona Charnley, Exeter Centre for the Circular Economy, University of Exeter, UK,

f.charnley@exeter.ac.uk

Prof. Phil Longhurst, Centre for Climate and Environmental Protection, School of Water, Energy and Environment, Cranfield University, College Road, Bedford MK43 0AL p.j.longhurst@ cranfield.ac.uk Prof. Simon Bolton, Faculty of Arts \& Sciences, Edge Hill University, St Helens Road, Ormskirk, Lancashire, L39 4QP, UK, simon.bolton@edgehill.ac.uk

Prof. Steve Evans, Centre for Industrial Sustainability, Institute for Manufacturing, University of Cambridge, 17 Charles Babbage Road, Cambridge, CB3 0FS, UK, se321@cam.ac.uk

\begin{abstract}
This paper investigates what enables sustainable design implementation from the front-end of new product development processes within the fast-moving-consumer-goods (FMCG) industry. Five FMCG cases at varying sustainability maturity levels were selected for survey-based interviews. The identified 11 factors and 32 sub-factors are presented under the three groups of Integrity, Instrumentality and Externality. Balanced focus on Growth and Consumer Insight and Maturity of infrastructure and consumer \& market are FMCG specific. The synthesis is presented in a framework explaining the precedence of the Integrity group factors before others. Quantitative analysis reveals that more positive, frequent evidence of factors and sub-factors is observed in higher sustainability maturity cases. The study confirms some of the existing but controversial factors across design and management fields, and uncovers two new FMCG specific factors. The study assists academics and industry practitioners in understanding what to consider when adopting sustainable design in the fastpaced business environment.
\end{abstract}

Keywords: sustainable design; front-end, new product development (NPD) process; fast-moving-consumer goods (FMCG), integrity, externality, instrumentality 


\section{Biographical notes:}

Curie Park is a research associate at Centre for Industrial Sustainability at University of Cambridge. Based on her experience as a product designer before joining the academia, her research focus is to expedite the positive impact creation through sustainable design of products, processes and systems. Currently she's working extensively with international partners to optimize innovation contest process to tackle sustainability issues by incorporating creative design process, systematic approach and multidisciplinary collaboration.

Fiona Charnley is associate professor of circular economy and co-director of the Exeter Centre for the Circular Economy at University of Exeter. Fiona works at the interfaces of design, manufacture and business modelling to investigate how organisations, across sectors, can transition towards a more innovative, sustainable and circular economy.

Phil Longhurst is Professor of Environment and Energy Technology and Head of the Centre for Climate and Environmental Protection (CEP) at Cranfield University. His research expertise focuses on diverting wastes from landfill, recovering value from material supply chains and reducing emissions from industrial supply chains. CEP is leading a programme of work on industrial decarbonisation including work on carbon capture \& storage and energy from waste with research councils, industrial partners and academic around the world.

Simon Bolton is professor of Innovation, Associate Dean for Enterprise and Employability and the director of the Productivity and Innovation Centre at Edgehill University. Simon's research focuses on understanding reasons for uncertainty and complexity in front-end innovation and how to improve individual, team and company's decision making. He is currently working with the Liverpool and Lancashire LEPs to improve productivity and innovation in growth potential SMEs.

Steve Evans is Director of Research at Centre for Industrial Sustainability, University of Cambridge. Steve leads a team studying what works for making industry sustainable, including research on radical resource productivity, sustainable business model innovation, and system transformation. He has founded various cleantech start ups and been Specialist Advisor to the UK House of Lords.

This article is a revised version of a $\mathrm{PhD}$ Thesis ' $\mathrm{C}$. Park (2015) Influencing factors for sustainable design implementation in the front-end of new product development process within the Fast-Moving-Consumer-Goods sector, Cranfield University, supervised by all the co-authors, with Fiona as the primary supervisor.

\section{Introduction}

\subsection{Calling for solutions for FMCG}

The Fast-Moving-Consumer-Goods (FMCG) industry is the world's 3rd largest industry sector, worth \$3.2 trillion (Hawken, et al., 2013). FMCG is characterised by mass linear manufacture of non-durable retail products (Park, 2015), currently sending $80 \%$ of materials to landfill, incineration or wastewater after a single use. Over $90 \%$ of products are being disposed of within 6 months (Ellen MacArthur 
Foundation, 2013), and the top 10 FMCG brands produce more green house gas than all the Scandinavian countries combined (Oxfam, 2014).

With characters of short lifespan and high turnover rates of the FMCG industry (Srinivasan and Wu, 2014), it is unquestionable that sustainable design solutions for FMCG products such as alternative product/ packaging materials, finish/ printing choices, production techniques/energy consumption, end-of-use circularity, and weight/ shape optimisation for distribution/transportation would bring about substantial positive sustainability impact. Recently, the serious marine pollution associated with single-use plastic has gained unprecedented public attention calling for urgent solutions. However, the adoption of sustainable design is not enough and consumers have relatively few sustainable products to choose from.

\subsection{Sustainable design and front-end NPD research gap}

Responding to growing environmental concerns, research on sustainable design matured significantly over the last decades (Dekoninck et al., 2016). Among the range of research topics including its competitive advantage, tools, frameworks, guidelines, drivers and barriers for implementation, the importance of the early adoption of sustainable design during the New Product Development processes (NPD) (e.g. Johansson, 2002; Bhamra, 2004, McLellan and Corder, 2013) is repeatedly emphasised. However, a research gap exists concerning what enables an early adoption of sustainable design consideration during the NPD from an FMCG perspective.

In this sense, this research takes a cross-disciplinary approach as the front-end of NPD research from the management perspective (e.g. Khurana and Rosenthal, 1998; Kim and Wilemon, 2002: Riel et al., 2013) can shed a light to address the gap.

\subsection{Objectives}

This paper aims to understand the enabling factors for sustainable design implementation at the frontend of the NPD process within the FMCG context. This is achieved through

a) An exploration of existing research into the factors of both sustainable design and NPD front-end management,

b) An investigation of the empirical evidence of five cases from the FMCG sector to validate and develop factors,

c) An examination of the roles and relative importance of the identified factors in relation to the companies' levels of sustainability maturity,

d) A synthesis of the factors in a conceptual framework.

This paper therefore provides a much-needed deeper inspection of the FMCG sector bringing out new insights from the overlooked synergy between the two disparate research areas. We anticipate this research would help the FMCG practitioners understand the areas to scrutinise within the company for 
a sustainable design implement from the beginning, and the academia with a comparison of the factors that are common or disparate from generic sustainable design factors.

\section{Theoretical background}

\subsection{Sustainable design and early adoption}

There has been a range of design terminologies referring to such design concept: from green, eco and sustainable design to more recently design for X (e.g. sustainability, environment, circular economy). Some academics claim they are interchangeable (Baumann et al., 2002; Kurk and Eagan, 2008) while each deserves their own definitions (Brezet and van Hemel, 1997). Green design emerged since 1970s referring to product design and development with a focus on single issues e.g. recyclable materials, subsequently ecodesign followed from the 1980s representing an approach to consider and integrate environmental aspects in the product development process (ISO, 2011). Sustainable design started to take over from 2000s as 'design that addresses all environmental, economic, and social impacts throughout the product's life cycle without compromising other criteria such as function, quality, cost, and appearance' (ECO2-IRN, 1995; Bhamra and Lofthouse, 2007). We claim that these different terms embody distinguishing approaches on issues of scale, ease of implementation, potential environmental benefits, and the focus of design activity (Fletcher and Goggin, 2001). The transition form 'green' to 'eco' to 'sustainable' represents a steady broadening of scope, and an increasing critical perspective on environment and design (Madge, 1997; Baumann et al., 2002). In this research, we adopted sustainable design for its broader scope; hence the literature search included the aforementioned collection of terminologies.

Along with the direct environmental benefits and the profitability of sustainable products and services (Tierney, 2002; Plouffe et al., 2011), sustainable design fosters the conversion of challenges into opportunities 'addressing product innovation, product quality improvement, cost reduction, risk minimization, and new market development' (Pigosso et al., 2013).

The earlier sustainable design is implemented, the more effective it can be (Sherwin, 2000; Bhamra, 2004, McLellan and Corder, 2013). The most influential decisions are made at the first steps of NPD process in regard of cost, look, materials, process, energy source, function, environmental impact, life expectancy, durability, and repairability of the product (Simon et al., 1997; Karlsson and Luttropp, 2006; Kurk and Eagan, 2008). These decisions determine how to incorporate the sustainability issues and relevant tools in the next stages (Poole and Simon, 1997; Sandstrom and Tingstrom, 2008).

However, despite the positive case made for the early adoption of sustainability considerations in the NPD process, a lack of integration is recognised between sustainable design and the broad context of product development, management and corporate strategy by many researchers (Baumann et al., 2002; Luttrop and Lagerstedt, 2006; Pigosso et al., 2013). Instead, the majority of the sustainable design research focuses on the rear end of the NPD stages, e.g. LCA (Munoz et al., 2009); metrics (Shuaib et al., 2014); and simulation (Van der Vorst et al. 2009). These tools can be viewed to be designed for 
the early stage of the design, but from the entire NPD process, the design stage take place from the 4th Stage: Development out of six stages within the Stage Gate Model by Cooper (1988). It has to be noted that adopting sustainability considerations to the NPD process in the front-end increase the complexity of the process. Hence adding sustainability perspective through established techniques is the most effective option (Goffin, 2012), i.e. 0, 1, and 2 of the Stage-Gate process (Cooper, 1988): the front-end.

'Front-end' is 'the period between when an opportunity is first considered and an idea is judged ready for development' (Kim and Wilemon, 2002). Although some argue that it comes before the formal and structured NPD (Koen et al., 2001), the current research considers the stage 0 to 2 of the Stage -Gate Model as the front-end of NPD.

The front-end activities are fundamental and the success or failure of a product is often determined during these stages (Cooper, 1988; Dwyer and Mellor, 1991; Moenaert et al., 1995; Langerak et al., 2004). The criticality of the front-end activities also applies to the sustainable design of products. The front-end is where a vision for a sustainable product is developed, while the front- end is commonly recognised as challenging to manage in general (Khurana and Rosenthal, 1998; Kim and Wilemon, 2002). If the sustainable design concept is not developed and discussed at an expert-level at the early stage, sustainability considerations are easily missed out during the following NDP stages. However, sustainable design at the front-end activities is not widely discussed, supposedly due to certain characteristics of the front-end innovation itself such as

a) Being intrinsically non-routine, dynamic, uncertain and unstructured

b) Being difficult to generalise

c) Having a low level of formalisation

(Khurana and Rosenthal, 1998; Kim and Wilemon, 2002; Sandstrom and Tingstrom, 2008)

Khurana and Rosenthal (1998) conducted in-depth case studies of 18 business units from 12 American and Japanese firms from various industry sectors. They suggest a fresh view to the success factors of front-end activities such as a holistic approach to effectively link business strategy, product strategy, and product-specific decisions. Four years later, Kim and Wilemon (2002) consolidated success factors of front-end activities, and the below ones among a total of 17 resonate with those of sustainable design implementation.

a) Cross-functional team responsible for the key activities

b) Project champion as a facilitator, communicator and motivator

c) Senior management to provide guidance of product strategy and plans

d) Alignment of new product plans, $\mathrm{R} \& \mathrm{D}$, process, and marketing

e) Communication among R\&D, engineering, and marketing functions 
Recently, an increasing number of studies on sustainable design implementation at the front-end of NPD started to emerge, e.g. Petala et al., (2010), Deutz et al. (2013), and Bocken et al., (2014). In the empirical study of Bocken et al. on the front-end of eco-innovation of 42 small and medium enterprises (SMEs) in the Netherlands, ecodesign was recognised as a form of eco-innovation. Their findings reinforce the consensus about the lack of understanding of eco-innovation mechanism at the front-end of NPD, and led to the following taxonomy of front-end eco-innovation's characteristics:

a) Satisfying (green) consumers and generating revenue are the main drivers

b) Systematic but informal manner

c) Multi-disciplinary, creativity skills and environmental knowledge are essential

d) Engagement with external stakeholders, e.g. consumers, suppliers to generate novel ideas

e) SME's front-end-eco-innovation is similar to larger companies

\subsection{Sustainable design factors and frameworks}

A number of empirical and discussion-based studies exist within the sustainability literature with a focus on the success factors and barriers for sustainable design implementation.

Johansson (2002)'s extensive coverage of success factors (Boks, 2006) recognised the common ground of NPD elements and the integration of ecodesign (p.105). Four out of six areas such as management, customer relationship, supplier relationship, and development process are common success factors for both product development and ecodesign integration; while competence and motivation are specific to the latter. However, the list of success factors needs an empirical validation, and misses some important factors which other research has identified, e.g. communication.

Dekonink et al., (2016) developed a conceptual framework of ecodesign implementation challenges. The novelty of this study lies in the key criteria of significant experiences in ecodesign within manufacturing. Their critical literature review of 46 existing studies of ecodesign implementation adopting the hypothetic-deductive approach to develop, test and refine a framework aggregated a total of 111 challenges. Lack of motivation and fitting with NPD timescale are two sub-themes under the management category that resonate with the current research, discussing the integration with new product development. While the fresh categorisation of strategy, tools, collaboration, management and knowledge sheds a light on the challenges from a different angle, it is unclear what they refer to as a framework.

Rossi et al., (2016) conducted a systematic review of research exploring barriers for the ecodesign methods and tools for the last 20 years. Their twofold classification of tool-related barriers and external barriers support the current research from a wider perspective in terms of the early application on the NPD, motivation, and customisation of tools. In the above two studies, it is difficult to argue that a table of the challenges listed them under a certain order has any explanatory role in this study. 
On the contrary, the circular design framework by Moreno et al. (2016) provides a fine example of comprehensive framework of circular design strategies mapped out against the circular business model archetypes and their value creation.

\subsection{FMCG specific studies in sustainable design factors}

Until today, few examples of factor analysis research offer empirical evidence with a FMCG focus, other than tool development (Diegel et al., 2010: Srinivasan and Lu, 2014). Petala et al. (2010) empirically examined the challenges for incorporating sustainability at Unilever analysing 202 NPD briefs within the food product projects. They concluded that incorporating sustainability in the NPD briefs did not guarantee results, along with success factors such as clear internal communication, tailormade eco design tools, clear environmental target, senior management commitment, and crossfunctional teamwork. Although this study is significant in addressing the FMCG sector, its limitation being a single case study relying on content analyses of project briefs would require more validity before applying to a larger FMCG context.

De los Rios and Charley (2017) investigated the role of design within 8 manufacturing firms including one FMCG. Taking circular economy as a path to product sustainability, the focus is on the systematic changes for closed-loop of materials. Analysing secondary data, the study articulates the required proficiencies ranging from deeper knowledge of material science, engineering techniques and operational processes, to knowledge in service design and a deep knowledge of human behaviour. As one FMCG was included among 8 cases, their cross-sectorial approach may not represent the FMCG, however their findings may apply to the sector.

\subsection{Aggregation of existing factors}

The literature review highlights necessity of a cross-disciplinary approach in examining the success factors for sustainable design implementation and the front-end of NPD. The review reveals that a substantial number of factors shares commonalities across sustainable design literature, and NPD front-end studies (Table 1).

Common factors are found both in sustainable design literature and front-end NPD/ innovation literature, as well as some controversial ones across the disciplines. The first column lists the factors under eight categories, divided into two groups of common and controversial factors. The second and third columns respectively depict the attributes of the factors and the authors from two research fields of sustainable design and NPD front-end innovation study. The top group of senior management support, internal communication, cross-functional team, and supportive corporate culture are the success factors that penetrate different research areas. 


\begin{tabular}{|c|c|c|c|c|}
\hline & \multicolumn{2}{|c|}{ Sustainable design implementation } & \multicolumn{2}{|c|}{ NPD front-end innovation } \\
\hline & Attributes & Authors & Attributes & Authors \\
\hline \multicolumn{5}{|c|}{ Common Factors } \\
\hline $\begin{array}{l}\text { Communicati } \\
\text { on }\end{array}$ & $\begin{array}{l}\text { Vertical / horizontal } \\
\text { (Within / between } \\
\text { teams) } \\
\text { Interpretive } \\
\text { structures } \\
\text { Clear internal } \\
\text { communication }\end{array}$ & $\begin{array}{l}\text { Lenox and Ehrenfeld (2000) } \\
\text { Johansson (2002) })_{\text {SEP }}^{[-7} \\
\text { Petala et al. (2010) }\end{array}$ & $\begin{array}{l}\text { Among R\&D, engineering } \\
\text { and marketing }\end{array}$ & $\begin{array}{l}\text { Khurana and Rosenthal (1998) } \\
\text { Kim and Wilemon (2002) }\end{array}$ \\
\hline $\begin{array}{l}\text { Senior } \\
\text { management } \\
\text { support }\end{array}$ & $\begin{array}{l}\text { Financial back-up: } \\
\text { budget / resources } \\
\text { allocation } \\
\text { Motivation } \\
\text { Incentive } \\
\text { Clear vision }\end{array}$ & $\begin{array}{l}\text { Ritzen and Bestow (2002) } \\
\text { Boks (2006) } \\
\text { Lee-Mortimer and Short (2009) } \\
\text { Petala et al. (2010) } \\
\text { Dekonink et al., (2016) }\end{array}$ & $\begin{array}{l}\text { Matching core team } \\
\text { capabilities to the role } \\
\text { played by senior } \\
\text { management }\end{array}$ & $\begin{array}{l}\text { Moenaert et al. (1995) } \\
\text { Khurana and Rosenthal (1998) } \\
\text { Kim and Wilemon (2002) } \\
\text { Goffin (2012) }\end{array}$ \\
\hline $\begin{array}{l}\text { Cross- } \\
\text { functional } \\
\text { team }\end{array}$ & $\begin{array}{l}\text { Critical decisions at } \\
\text { early stages }\end{array}$ & $\begin{array}{l}\text { Borsboom (1991) } \\
\text { de Ron (1998) } \\
\text { Stoyell et al. (1999) } \\
\text { Johansson (2002) } \\
\text { Petala et al. (2010) }\end{array}$ & Horizontal cooperation & $\begin{array}{l}\text { Cooper and Kleinschmidt (1986) } \\
\text { Khurana and Rosenthal (1998) } \\
\text { Kim and Wilemon, (2002) }\end{array}$ \\
\hline $\begin{array}{l}\text { Corporate } \\
\text { culture }\end{array}$ & $\begin{array}{l}\text { Supporting } \\
\text { sustainable goals by } \\
\text { individuals and } \\
\text { corporate }\end{array}$ & Lee-Mortimer and Short (2009) & Collaborative culture & $\begin{array}{l}\text { Murphy and Kumar (1997) } \\
\text { Khurana and Rosenthal (1998) } \\
\text { Kim and Wilemon (2002) }\end{array}$ \\
\hline \multicolumn{5}{|c|}{ Controversial Factors } \\
\hline \multirow[t]{2}{*}{$\begin{array}{l}\text { Sustainability } \\
\text { (project) } \\
\text { champions }\end{array}$} & $\begin{array}{l}\text { Knowledgeable, } \\
\text { inspiration, } \\
\text { motivated } \\
\text { individual }\end{array}$ & $\begin{array}{l}\text { Lenox and Ehrenfeld, (1997) } \\
\text { McAloone et al., (1998) } \\
\text { Simon et al. (2000) } \\
\text { Johansson (2002) }\end{array}$ & \multirow[t]{2}{*}{$\begin{array}{l}\text { Project owners: } \\
\text { help drive the front- end } \\
\text { give breath and scope }\end{array}$} & $\begin{array}{l}\text { Moenaert et al. (1995) } \\
\text { Khurana and Rosenthal (1998) } \\
\text { Kim and Wilemon (2002) }\end{array}$ \\
\hline & Dispute: no existence & Boks (2006) & & \\
\hline \multirow[t]{2}{*}{ Tools } & Customized tools & $\begin{array}{l}\text { Simon } \text { et al. (2000) } \\
\text { Luttropp and Lagerstedt (2006) } \\
\text { Diegel et al. (2010) } \\
\text { Petala et al. }(2010) \\
\text { Srinivasan and Lu (2014) } \\
\text { Rossi et al.,., (2016) }\end{array}$ & \multirow[t]{2}{*}{ Appropriate tools } & Schilling and Hill (1995) \\
\hline & $\begin{array}{l}\text { Dispute: Not being } \\
\text { adopted by } \\
\text { industry }\end{array}$ & Lee-Mortimer and Short (2009) & & \\
\hline \multirow[t]{2}{*}{$\begin{array}{l}\text { Consumer } \\
\text { orientation }\end{array}$} & $\begin{array}{l}\text { Consumer focus } \\
\text { Consumer education }\end{array}$ & Johansson (2002) & \multirow[t]{2}{*}{$\begin{array}{l}\text { Emphasize consumer } \\
\text { involvement }\end{array}$} & $\begin{array}{l}\text { Khurana and Rosenthal (1998) } \\
\text { Kim and Wilemon (2002) }\end{array}$ \\
\hline & Dispute: No need & Short (2008) & & \\
\hline \multirow[t]{2}{*}{$\begin{array}{l}\text { Formalised } \\
\text { Structure }\end{array}$} & $\begin{array}{l}\text { EMS (Environmental } \\
\text { Management } \\
\text { Systems) }\end{array}$ & Simon et al. (2000) & \multirow{2}{*}{$\begin{array}{l}\text { Formalized systems } \\
\text { Managing the interface } \\
\text { functions and } \\
\text { departments }\end{array}$} & $\begin{array}{l}\text { Khurana and Rosenthal (1998) } \\
\text { Kim and Wilemon (2002) }\end{array}$ \\
\hline & $\begin{array}{l}\text { Dispute: Necessary } \\
\text { but not sufficient }\end{array}$ & & & \\
\hline
\end{tabular}

The bottom group presents contradicting factors across the disciplines including project/ sustainability champion, usage of tools, consumer orientation, formalised structure are controversial factors. 
Sustainable champions (project champion for front-end NPD) is claimed as a success factor by many authors from both sustainable design and front-end studies (e.g. Lenox and Ehrenfeld, 1997; Simon et al., 2000; Kim and Wilemon, 2002), while disputed as non-existent by Boks (2006). Similarly, usage of tools is claimed as useful by some sustainable design authors (e.g. Simon et al., 2000; Luttropp and Lagerstedt, 2006), and disputed by the other (Lee-Mortimer and Short, 2009). Consumer orientation and formalised structure are also claimed to be necessary by the front- end NPD academics, while some sustainable design authors disagree of its necessity.

The literature findings informed the questionnaire for empirical data collection in the following steps. The next sections investigate existing common and controversial factors and identify new factors within the real-life FMCG contexts.

\section{Methodology}

The research draws on the pragmatic approach of claiming knowledge out of actions, situations and consequences using all possible approaches to understand the phenomenon (Cresswell, 2003). Adopting mixed methods (Robson, 2011), we collected both qualitative and quantitative data at five FMCG companies for case studies (Yin, 2003). The data collection was triangulated through crosschecking the data from survey-based interviews, in-situ observations and document analysis. The empirical data then was analysed using thematic coding to inform the presented framework.

\subsection{Questionnaire survey}

\subsubsection{Literature-basis}

The research started with reviewing existing literature to understand the identified challenges for sustainable design implementation and the relevant circumstances. Starting from 360 broadly relevant articles under the keywords of sustainable design, eco design, green design, design for sustainability, design for environment, FMCG, NPD, front-end, and success factors, we narrowed down to 22 key papers under five categories: sustainable design factors (other similar design terminologies inclusive), sustainable management, front-end, and NPD Stage-Gate.

The synthesis of the literature findings from a range of disciplines from design, engineering and management research helped the authors identified the disconnection among these research fields which could generate practical synergy to understand the phenomenon of sustainable design implementation during the front-end of NPD.

We identified 8 key items around sustainable implementation (Table 1), which were either common or controversial in two different contexts: the general front-end of NPD context and the sustainable design perspective in the non-industry specific industry context. 


\subsection{2. $1^{\text {st }}$ Questionnaire}

Based on the literature findings, the first questionnaire was formulated under two sections of 1) common NPD success factors including four items of consumer involvement, senior management support, internal communication and cross-functional team; 2) sustainable design key factors including six items of common use of language, sustainability champion, sustainability tool(s), sustainability in brand vision, company culture for sustainability, sustainable design practice and personal aspects.

To collect quantitative data, three to six closed questions were asked for each item in terms of three perspectives of importance, frequency and effectiveness adopting the 1-5 Likert scale. To collect qualitative data, an open question of the definition of success was asked which helped gather fuller insights, which could have not been captured otherwise. The vast magnitude and the complexity of the question system resulted the questionnaire that contains total of 610 questions over 24 pages (See Appendix 1 for an example page).

\subsubsection{2 ${ }^{\text {nd }}$ Questionnaire}

The $2^{\text {nd }}$ Questionnaire was developed to verify and further elaborate the results of the $1^{\text {st }}$ Questionnaire. While still keeping the 12 items and the $1-5$ Likert scale format from the $1^{\text {st }}$ version, the $2^{\text {nd }}$ version is designed to focus on the design context. This 6-page version had 72 questions including 13 open questions (See Appendix 2 for an example page).

\subsection{Five FMCG companies: Comparative case studies}

Case study method is a compelling and robust method that helps examine the present phenomenon in the real-world context (Herriot and Firestone, 1983). Case study is suitable for this research to gain an in-depth understanding of the FMCG context and the factors (Yin, 2003). We have developed a six case selection criteria to maintain the quality and variety of the samples as below.

a) Operating in the FMCG sector, manufacturing and retailing FMCG products.

b) Measurable sustainability commitment: a track record was needed to measure their sustainability history and the maturity level.

c) Market leaders: substantial market share.

d) A certain sustainability maturity level (SML): each represent different levels across 5 sustainability stage models.

e) Access to employees at various positions: ensuring triangulation of opinions across the company hierarchy.

f) Access to varying functions of the NPD process: for the triangulation of findings across company functions. 
A total of five companies participated in the data collection among the contacted nine companies. Table 3.2.1. illustrates the detail of the case companies. To capture the balanced view from varying perspectives, interviews were conducted with multiple interviewees at various functions and positions within each case company.

Table 2 Five FMCG cases

\begin{tabular}{llllll}
\hline & Case A & Case B & Case C & Case D & Case E \\
\hline $\begin{array}{l}\text { Business } \\
\text { Sector }\end{array}$ & $\begin{array}{l}\text { Cosmetics and } \\
\text { personal care } \\
\text { products }\end{array}$ & $\begin{array}{l}\text { Cosmetics and } \\
\text { personal care } \\
\text { products }\end{array}$ & $\begin{array}{l}\text { Cosmetics, } \\
\text { personal care } \\
\text { products and cleaning } \\
\text { products }\end{array}$ & $\begin{array}{l}\text { Beverages, } \\
\text { Household goods and } \\
\text { Cleaning products }\end{array}$ & $\begin{array}{l}\text { Healthy drinks and } \\
\text { food }\end{array}$ \\
\hline Location & Brazil & South Korea & $\begin{array}{l}\text { Multinational } \\
\text { (USA origin) }\end{array}$ & South Korea & United Kingdom \\
\hline $\begin{array}{l}\text { Design } \\
\text { team }\end{array}$ & External & Internal and external & Internal and external & Internal and external & External \\
\hline Size & 18,000 employees & 11,600 employees & 95,000 employees & 9,500 employees & 450 employees \\
\hline $\begin{array}{l}\text { Sustainab } \\
\text { ility } \\
\begin{array}{l}\text { Maturity } \\
\text { Level }\end{array}\end{array}$ & $\begin{array}{l}5 \\
\text { Purpose and } \\
\text { passion \& Fully } \\
\text { incorporated }\end{array}$ & $\begin{array}{l}3 \\
\text { Beyond compliance } \\
\text { \& Regular basis }\end{array}$ & $\begin{array}{l}2 \\
\text { Compliance \& Non- } \\
\text { consolidated }\end{array}$ & $\begin{array}{l}\text { Pre-compliance and } \\
\text { little experience }\end{array}$ & $\begin{array}{l}\text { Integrated strategy \& } \\
\text { Systematically } \\
\text { incorporated }\end{array}$ \\
\hline
\end{tabular}

In order to determine the sustainability maturity level (SML) of each case, an extensive review of nine sustainability maturity assessment models was conducted including the aspects of the process maturity, organizational maturity, process capability and project maturity. Two sets of metrics (Table 3) were adopted for their relevance and structure (Hallstedt et al., 2010; Pigosso et al., 2013).

Table 3 Sustainability Maturity Level Metrics (Source: Five stages of sustainability Integration into Business Activities by Hallstedt et al., 2010; Evolution Level in Ecodesign by Pigosso et al., 2013)

\begin{tabular}{ll}
\hline SML (low to high) & \\
\hline $\begin{array}{l}\text { 1. Pre-Compliance } \\
\text { \& little experience }\end{array}$ & $\begin{array}{l}\text { Ignoring sustainability and opposing related regulations. Very little experience in eco design, do not yet } \\
\text { completely apply eco design practices. Environmental issues and benefits are not explored yet. Understands } \\
\text { eco design concepts, can define internal/ external drivers for its adoption, carry out benchmark study. }\end{array}$ \\
\hline $\begin{array}{l}\text { 2. Compliance \& } \\
\text { non-consolidated }\end{array}$ & $\begin{array}{l}\text { Obeying laws and regulations on labour, environment, health and safety. Familiar with some eco design } \\
\text { practices and potential benefits. Pilot projects are implemented, focusing on the incremental improvement of } \\
\text { existing products, emphasis on specific phases of the lifecycle. Non-consolidated approaches. Endeavors to } \\
\text { generate awareness and motivation for eco design. Adopts formal eco design programme. (A)LCA } \\
\text { [(Abridged) Life Cycle Assessment] tools used. }\end{array}$ \\
\hline $\begin{array}{l}\text { 3. Beyond } \\
\text { Compliance \& } \\
\text { regular basis }\end{array}$ & $\begin{array}{l}\text { Recognizing the opportunity to cut costs mainly through higher resource efficiency and waste reduction, } \\
\text { leading to both financial and ecological gains. Sustainability is still separated from core business development. } \\
\text { Recognizes the importance and benefits of eco design. All the NPD projects consider environmental issues on } \\
\text { a regular basis. Eco design is technically integrated. }\end{array}$ \\
\hline $\begin{array}{l}\text { 4. Integrated } \\
\text { Strategy \& } \\
\text { systematically } \\
\text { incorporated }\end{array}$ & $\begin{array}{l}\text { Sustainability is integrated in the company's vision and informs key business strategies to be more successful } \\
\text { than competitors through innovation, design and improved financial risk assessments. According to Willard, } \\
\text { very few companies in the world have yet arrived at this stage. Eco design is incorporated systematically into } \\
\text { the beginning of NPD. Eco design influences business, managerial, and technical areas. New concepts (e.g. } \\
\text { product/service systems) can be developed. }\end{array}$ \\
\hline
\end{tabular}


5. Purpose and Passion \& fully incorporated
This is not actually the next stage of development but rather a special type of company, being originally designed to 'help saving the world'. Environmental issues are fully incorporated into the company's corporate, business and product strategies, reinforcing the decision-making processes. Aims at system innovation: developing new products and services that require changes in the business models and infrastructure

Based on the metrics, the SML of each case were determined by analysing the publicly available data e.g. product examples, sustainability reports, existence of dedicated sustainability department and official recognitions. The decision was also triangulated in-situ observation and interview data. The analysis resulted the each case company distributed their SML from 1 to 5.

\subsection{Data collection and analysis}

\subsubsection{9 interviews and triangulation}

14 interviews were undertaken at two companies (case A and B) followed by five interviews at three companies (Case C, D and E) for verification of the first findings.

Table 4 Details of the interviews and supporting data

\begin{tabular}{|c|c|c|c|c|c|}
\hline & Case A & Case B & Case C & Case D & Case E \\
\hline Interview type & Face-to-face & Face-to-face & $\begin{array}{l}\text { Face-to-face/ } \\
\text { telephone }\end{array}$ & $\begin{array}{l}\text { Face-to-face/ } \\
\text { telephone }\end{array}$ & Face-to-face \\
\hline Interviewees & $\begin{array}{l}\text { 1. Packaging } \\
\text { development } \\
\text { coordinator } \\
\text { 2. Marketing } \\
\text { manager } \\
\text { 3. Corporate brand } \\
\text { manager } \\
\text { 4. Strategic planning } \\
\text { director } \\
\text { 5. Sustainability } \\
\text { R\&D manager } \\
\text { 6. Eco design } \\
\text { manager } \\
\text { 7. R\&D researcher }\end{array}$ & $\begin{array}{l}\text { 1. Sustainable } \\
\text { growth director } \\
\text { 2. Corporate } \\
\text { sustainability } \\
\text { manager } \\
\text { 3. Brand manager } \\
\text { 4. Design manager } \\
\text { 5. R\&D manager } \\
\text { 6. R\&D researcher } \\
\text { 7. Project } \\
\text { communication } \\
\text { coordinator }\end{array}$ & $\begin{array}{l}\text { 1. Senior design } \\
\text { manager } \\
\text { 2. R\&D director } \\
\text { (Former) }\end{array}$ & $\begin{array}{l}\text { 1. Senior design } \\
\text { manager } \\
\text { 2. Senior packaging } \\
\text { designer }\end{array}$ & $\begin{array}{l}\text { 1. Packaging } \\
\text { specialist }\end{array}$ \\
\hline $\begin{array}{l}\text { Data } \\
\text { collection } \\
\text { phase } \\
\end{array}$ & Phase 1: in-depth & Phase 1: in-depth & Phase 2: verification & Phase 2: verification & Phase 2: verification \\
\hline $\begin{array}{l}\text { Analysed } \\
\text { documents }\end{array}$ & $\begin{array}{l}\text { 1. Official website } \\
\text { 2. Sustainability } \\
\text { report (2012) } \\
\text { 3. Market research } \\
\text { report } \\
\text { 4. Conference } \\
\text { presentation }\end{array}$ & $\begin{array}{l}\text { 1. Official website } \\
\text { 2. Sustainability } \\
\text { report (2012) } \\
\text { 3. Market research } \\
\text { report } \\
\text { 4. E-newsletter } \\
\text { articles }\end{array}$ & $\begin{array}{l}\text { 1. Official website } \\
\text { 2. Sustainability } \\
\text { report }(2012,13) \\
\text { 3. Market research } \\
\text { report } \\
\text { 4. External reports } \\
\text { and books }\end{array}$ & $\begin{array}{l}\text { 1. Official website } \\
\text { 2. Sustainability } \\
\text { report (2012) } \\
\text { 3. E-newsletter } \\
\text { articles }\end{array}$ & $\begin{array}{l}\text { 1. Official website } \\
\text { 2. Management } \\
\text { research report }\end{array}$ \\
\hline $\begin{array}{l}\text { In-situ } \\
\text { observations }\end{array}$ & $\begin{array}{l}\text { Interview stand-by } \\
\text { Visit office floors } \\
\text { Visit marketing } \\
\text { department (separate } \\
\text { location) } \\
\text { Lunches / Tea times } \\
\text { Factory Tour }\end{array}$ & $\begin{array}{l}\text { Interview stand-by } \\
\text { Visit office floors } \\
\text { Visit design labs } \\
\text { Visit company } \\
\text { library } \\
\text { Lunch }\end{array}$ & $\mathrm{n} / \mathrm{a}$ & $\mathrm{n} / \mathrm{a}$ & $\begin{array}{l}\text { Interview stand-by } \\
\text { Company } \\
\text { presentation } \\
\text { Company tour }\end{array}$ \\
\hline
\end{tabular}


For the triangulation of the qualitative data, information for publically available documents e.g. official websites, annual sustainability reports and the third-part market reports were used as well as in-situ observation field notes.

\subsubsection{Qualitative data analysis: 2-phased thematic coding}

The qualitative data then was analysed using thematic coding. Thematic coding summarised key themes emerging from the multitudinous qualitative data (Robson, 2011). In the first coding analysis, the original 12 items were used as the codes (themes) and 25 sub-themes were inductively determined by cross-reviewing the transcriptions, previous research and research questions. The first round outcomes served as the basis for the further investigation through the $2^{\text {nd }}$ questionnaire, which subsequently allowed a refinement into the final 11 factors and 32 sub-factors. The original items were merged with others, and some common factors were elaborated into sustainable design specific factors.

\subsubsection{Quantitative data analysis: descriptive statistics}

Descriptive statistics was deployed to summarise the questionnaire answers and reveal the distribution tendency of positive, negative and neutral (Robson, 2011). Data from the Likert analysis of importance, frequency and efficiency was used to examine the recurring patterns of the co-relationships between positive or negative evidence and the sustainability maturity level (SML) of each company.

\subsubsection{Data reduction and Conceptual framework}

The integration of the data took place in the form of data reduction and data comparison (Robson, 2011; Onwuengbuzie and Teddlie, 2003). The items from the literature findings were dissected and synthesised to answer the research questions.

In addition, the integration of qualitative and quantitative data allowed summarising the complex mass of the data into a number of understandable themes and a conceptual framework. The analysis excavated the co-relationship of the identified 11 factors, in terms of the timely orders, the conceptual hierarchy, and the closeness with one another.

\section{Findings}

This section describes the results of the data analysis from five FMCG cases. The initial items from the literature were reduced after the empirical survey and interview data analysis to 11 factors. 32 subfactors were added elaborating the specificity of the front-end of the NPD process, and two factors are specifically for the FMCG context.

\subsection{Balanced focus on growth and consumer insights}

The most conspicuous finding from this study is the new FMCG specific factor of balanced focus on growth and consumer insights. Whilst growth and consumers are common interests for all the cases in 
this study, the difference between high and low SML cases can be found in the balance of their focus. Successful sustainable design implementation in the FMCG sector is possible when the focus of the growth and consumer insights is not only on the finance but also the rest of the three sustainability pillars: environment and society. Six associated sub-factors were identified:

A) Careful balance of Triple Bottom Line: High SML cases pursue growth with the careful balance of environmental responsibility, social benefits, and economic viability. For instance, Case A runs the rewarding policy to acknowledge individual's contribution to growth only when all three aspects are improved.

B) Balanced reliance on consumer insight: Blind reliance on consumer insight can weaken sustainable product development, especially when consumers are less concerned about sustainability. The high SML companies clearly show their leadership in consumer relations and tend to avoid thorough or exclusive reliance on consumers' demands.

“Don't be led by consumers. We can no longer rely on consumers to drive market change." (Case E).

C) Equal sustainability emphasis in brand portfolio: $80 \%$ of the case companies show a higher attention level to sustainability aspects in certain brands across the brand portfolio. In other words, rather than equally maximising the sustainability of the products in every brand that the company carries, one or two brands work as the representative of the sustainability practice offsetting the nonsustainable aspects of other brands such as over-packaging or unrecyclable materials usages. This type of offsetting of environmental / social impacts between the sub-brands can be considered greenwashing.

D) Marketing dominance avoidance: In cases $A, B$ and $D$, marketing department had more power in decision-making at the front-end of NPD than other functions. Not only is this in contradiction with the emphasis on teams' cross-functionality, but can also endanger sustainability approaches as marketers are often in a position to prioritize profits over sustainability.

"All the decisions are made by the marketing director." (Case D).

E) Economy of scale flexibility: Whereas the high SML companies do not use size as an excuse, the two mid/low companies were observed to complain either that the huge size of existing manufacturing facilities hinders the sustainability investment (case $\mathrm{C}$ ), or the production volume is too nominal to afford to buy sustainable materials in bulk (case B). Flexibility that keeps up with the sustainability goal handling the economy of scale can be the win-win strategy. 
F) Speed constraint flexibility: Flexibility is critical to maintain sustainability consideration throughout the busy NPD process. As the title of the sector (i.e. Fast-Moving-Consumer-Goods) explicates, high speed NPD characterises this area, producing products at a fast turnover is fundamental for a business success. However, companies that are less flexible with time are more likely to overlook the sustainability consideration attributing to busy schedules.

"The consumer goods have to be done really quickly. Applying sustainability one by one is a pure luxury." (Case C).

\subsection{Maturity of external contexts: consumer, market and infrastructure}

Another FMCG-specific factor is the maturity of external context, which would not be applicable outside FMCG. The maturity of external contexts such as consumer, market, government and infrastructure, plays a key role in successful sustainable design implementation in the FMCG context. Even if other factors are in place, this factor can act as a potential barrier, and the implementation of sustainable design is inevitably discouraged from the beginning.

A) Maturity of consumer / market: If the target market or consumers are not mature enough to recognize the sustainability features of a product and make a purchase, the company's economic sustainability can easily be at risk. The lack of request from the market or consumers is a hindering factor for company's adoption of a sustainable design approach (Short et al., 2012). The fact that FMCG products demand relatively low financial/mental investment from the consumer can accelerate the knowledge-behaviour gap. According to Kollmuss and Agyeman (2002), consumers often make purchase decisions that misalign with what they say. Case B, D, and E provide further evidence of this phenomenon.

"They say eco, environmentally-friendly, but they say, 'I bought it just because it was buy 1 get 1 free." (Company D).

B) Maturity of infrastructure: No matter how enthusiastic the company is, national level infrastructure such as recycling systems, depending on governmental support, impacts the sustainability practice of individual business. Unlike other factors mentioned above, no actions are required here from companies. However, if the high SML companies are more likely to address the infrastructure-related challenges, mid-to-low SML companies tend to use it as an excuse for neglecting sustainability practice.

\subsection{Firm and knowledgeable Senior Leadership}

In general, senior management support is well known to be foremost and critical for successful 
sustainable design implementation from the front-end of NPD (Lee-Mortimer and Short, 2009; de Medeiros et al., 2014; Felekoglu and Moultrie, 2014). While confirming the previous finding, the current research specifically articulates the importance of verbal / non-verbal actions and proactive mind-sets towards sustainability practice from top managers. The three sub-factors necessary for effective senior management support are;

A) Firm sustainability leadership: Strong leadership makes middle management more confident to put into operations sustainability practice and aligns the employees to the sustainability cause. A failure to maintain firm leadership throughout the execution of sustainability goals and strategies allows alternative considerations to take priority, such as profitability, and weakens the sustainability motivation and incentivisation. High SML cases showed strong support for this factor,

"The founder is a very strong reference. His personal life and professional life are the cause. Our founders are very strong leaders. “(Company A)

Whereas the medium level showed a concern about the firmness of the leadership.

"We need a unshakable senior leadership. No matter how hard we want to push sustainable design at the bottom, if they are not enthusiastic to overcome the challenges... at the higher error rate in using recycled plastic, people often say 'well, let's use virgin material.", (Company B)

B) Familiarity with sustainability principles: Poor understanding of sustainability principles of the core team members can stifle the sustainability implementation in a concrete and constant manner (Short et al., 2012).

C) Rewarding individuals for sustainability achievement: A financial incentive scheme rewarding individual improvement in sustainability practice is an effective way for senior managers to encourage employees.

\subsection{Coherent Sustainability Vision}

The strong leadership provides a coherent sustainability vision, being embedded from the top (LeeMortimer and Short, 2009). A permeated and well-aligned sustainability vision with a company's general vision and company culture are therefore two necessary conditions of a 'proactive approach to sustainability' (Maletic et al., 2014). In addition, the study captured the tendency of stronger supporting evidence in the high SML cases with the two sub-factors as below:

A) An alignment with the company's general vision: Among the five cases, three mid/low rank Sustainability Maturity Level (SML) companies had separate visions for their business and sustainability, where the latter was hidden to the majority of employees.

"Probably there is something, as far as I understand. The vision seemed to have been 
proclaimed. But personally I don't really know.” (Case B).

B) A dissemination throughout the company's philosophy and daily activities: Two high SML cases: A and E showed a deep permeation of sustainability vision in the companies' beliefs and the employees' everyday activities. This recurring pattern among high SML companies indicates a better awareness and embodiment of their sustainability vision than among mid/low SML cases, where it was often seen to overlap with the company's general vision.

"We always talk about it. There is no way not to talk about it. We believe in this. We are born with this and living with it!" (Company A)

\subsection{Supportive corporate culture: Transparency, Legacy, Behaviour, Belief, Structure and Citizenship}

The concept of the 'intangible' side of the working ambience i.e. "soft side" (Boks, 2006), or the organisational "environment" (Lee-Mortimer and Short, 2009), presents some common features with corporate culture. Supportive culture of sustainability enables successful sustainable design implementation from the front-end of NPD. It fosters debates of whether to adopt sustainability practice and design into business, and is achieved by accumulation of shared values and beliefs, norms and behaviour over time (Deshpandé and Webster, 1989). This study establishes six sub-factors in regard of corporate culture with a supporting evidence from cases as below:

A) Transparency: A public disclosure of financial administration, revenue streams and business practices, as well as information on the manufacturing processes, material supply chain, waste management, energy usage, and the social and environmental impact of products is an imperative but one of the rare sub-factors displayed across all cases, with even the lowest SML case (D) agreed.

“My company doesn't tell lies or hide anything. We put a high value on fidelity." (Company D)

B) Legacy: Defined as 'the accumulation of sustainability practices within the company over a period of time' in this research, legacy was seen to motivate sustainability-enthusiastic employees to join the company, and boost their pride after they've joined. are well aware of. An interesting observation was from the medium SML case (Company C) explicating the focus of the company, which is $100 \%$ consumer driven referring back to the 4.1.1.

"My view is that our sustainability legacy mirrors the population." (Company C)

It is noticeable that high SML cases tend to have a strong legacy, which their employees. 
C) Behaviour: In this research, sustainability behaviour refers to the daily practices of the company and its employees, and encompasses a number of internal and external sustainability-related activities. The observed internal activities include carpooling, cycling to work (Case A), zero waste movement, quality food catering and equal access to welfare services (Case E). External activities include philanthropic volunteer jobs (Case B) and the investment to sustainability.

D) Belief: Along with behaviour and norm, belief is one of the key components of corporate culture (Deshpandé and Webster, 1989). High SML companies (A, E) tend to believe in their sustainability practice and its future influence, whereas mid/low companies' (B, C and D) first and foremost beliefs are focusing on meeting consumer's needs.

"Sustainable design is often seen as a limitation but it can be seen as an opportunity." (Company E)

E) Structure: This research confirms that a systemised structure enables sustainability to be recognised as a functional requirement, and a way to increase company's process efficiency (Case A, B and E) confirming Maletic et al. (2013). It helps address the risk of sustainable design being just an add-on design criterion, by providing sustainability an inherently fundamental position in the design process (Deutz et al., 2013). For instance, Case E was in the process of writing up detailed procedures in support of specific sustainability requirements. Whereas the low SML case (Company D) was negative and denial about their structure for sustainability.

"No way, no structure at all! We are completely random. We sometimes do it. Sometimes don't." (Company D)

On the contrary, the high SML case was confident in its strong structure for sustainability practice.

"We have a very defined project management process here and pretty much every project is following it. We always have great process... well structured. We've got teams, champions, and it's all in our vision." (Company E)

F) Citizenship: Corporate citizenship is defined as balancing the expectations of stakeholders with managing of a successful business, synonymising with corporate responsibility or the triple bottom line (Mirvis and Googins, 2006). High SML cases make the positive examples likely to guide society and other businesses. Case $\mathrm{E}$ has an explicit acknowledgement of its role in the society stating:

"Leaving things in a little bit better than we find them." (Company E) 


\subsection{Motivated, Satisfied and Ambitious Individuals}

Along with the above supporting corporate culture, the individual attitude was found to be another intangible factor for sustainable design implementation from a socio-psychological perspective. In addition to the motivation element developed by Johansson (2002), this research presents the following three sub-factors categorised by different time scales.

A) Motivation based on the company's past sustainability practice: Individual's sustainability motivation based on the sustainability legacy penetrating the company history reinforces the employee's voluntary sustainability behaviours. Employees at the high SML cases are typically aware of their company's sustainability reputation before joining, and their enthusiasm increases after joining the company.

B) Satisfaction about company's present sustainability practice: The high SML company employees take pride in their company's current engagement in sustainability practice. They show both high satisfaction and high enthusiasm.

“It's a miracle! I believe it's because of the very [sic] special and engaged people.” (Case A)

C) Ambition about the company's future sustainability practice: As a general rule, the employees at the high SML companies tend to be more ambitious about how the company should operate in the future. Although they are content now, they aspire to push the boundary further, sustainability being a relative concept. Despite the challenge raised by the assessment of individual's mentality, recurring patterns of high ambition were captured through probing and comparing the details of interview transcription among high SML companies' employees.

\subsection{Healthy and multi-channel Internal Communication}

Internal communications deeply influence the design activities as it enables the effective dissemination of the sustainability vision, and ensures the successful execution of the strategies in company practice from the front-end of the NPD process (Johansson, 2002). While supporting Johansson, we captured two sub-factors to support the importance of the internal communication as below:

A) Healthy interpersonal relationships: Ease of interaction and constant communication between hierarchical positions, within the NPD process appears helpful to build mutual trust and provides a first facilitating step toward open discussions of sustainability issues.

"Not only within the team, but also the factory workers, designers, researchers and sales persons are all in good relationship." (Company B) 
B) Variety of channels: As stressed by Tien et al. (2005), varying open communication channels are important for successful NPD. The list includes formal communication channels such as regular briefings and general meet-ups and project presentations, as well as informal channels such as casual conversations, email responses, and quick requests. It is something that the majority of the sample cases emphasised, making the case for a healthy internal communication at the corporate level and efficient execution at the project level regardless of the SML.

'We casually exchange ideas when we bump into each other or over lunch. So idea exchanges accumulate, which makes it easier when it comes to the actual development process." (Company B)

"Formal meetings, everyday conversations, emails, text messages, it varies. It's quite easy to communicate.” (Company D)

\subsection{Clearly agreed terminology}

There have been contrasting views on whether varying terminologies and definitions regarding sustainability-related design activities are interchangeable (Keoleian and Menerey, 1994; Madge, 1997; Sherwin, 2000; Short et al., 2012) or a unified usage is important (Glavic and Lukman, 2007; Hallstedt et al., 2010).

This research verifies the positive role of clear terminology in successful sustainable design implementation in industry practice. Two supporting sub-factors are:

A) Agreed definition on sustainability terminology: Common and consolidated terminology and definition lower the risks of confusion within the NPD team, as well as between company and consumers (Short et al., 2012). The gap in understanding between the academic community and 'people on the factory floor' clearly exists, and hinders practitioners from taking more precise measures upon the sustainability needs.

“They all sound the same.”(Case B)

B) Sense of sharing the same goal: Data demonstrates that different terminologies can be used in a mixed fashion. In this context, many interviewees argued that understanding each other remains key regardless of terminologies. However, given that one of the measures of sustainability maturity is the existence of a long-term goal within the company, the importance of clarifying what they mean, and sharing it with stakeholders in a consolidated fashion cannot be overemphasised.

\subsection{Project-Level Sustainability Champion}

This study defines sustainability champion (i.e. environmental champion/ coordinator/ advisor) as a person embedded within the company or projects, conveying motivation and providing sustainability 
knowledge into design (Velhurst and Boks, 2014; Kim and Wilemon, 2002; Pujari, 2006). This research identified a couple of aspects of sustainability champion.

A) Project level involvement: In some mid/low cases (B and C), the corporate level sustainability officer is considered as a champion. The data from A and $\mathrm{E}$ shows that in order to cater for the daily necessity of the NPD team, the champion is a role for someone actively involved in the NPD project.

B) Official vs. voluntary: As opposed to many academic claims (Simon et al., 2000; Kim and Wilemon, 2002), none of the cases had an officially appointed champion. Instead, enthusiastic volunteers were observed to exist at the project level. Verhulst (2012) reveals a similar pattern in the name of sustainability ambassador, either official or voluntary in her case studies. Notably, the mid/low SML companies $(\mathrm{B}, \mathrm{C})$ do not feel the need for a champion because most of the NPD projects are conducted in a business-as-usual manner with little sustainability consideration.

\subsection{Timely introduction of Customised Sustainability Tools}

The high and mid/low SML groups empirically show a clear polarisation towards sustainability tools. High SML cases appreciate the benefit of utilising tools, while lower-level groups show low expectations as they either do not have the tools nor aware of them. Although the effectiveness of sustainability tools is controversial in terms of the practical applicability during NPD (e.g. Ritzen and Beskow, 2002; O'Hare, 2010), this research advocates the need of tools with the following prerequisites:

A) Customisation for company context: Whilst tools are often seen to be overly complicated or unfit for a company's own NPD needs and circumstances, high SML cases (A and E) are proactive in using them through both customising existing tools or developing their own.

"We have a series of guidelines that you must follow throughout the process from stage 0 to $2 . .$. to have an eco design product... we are working on this very well articulated guideline that everybody will be able to follow." (Company A)

B) Timely introduction: Tools can slow down or complicate the existing NPD process, thus caution introduction at a right timing is recommended not to discourage busy NPD members to adopt them.

\section{11. Equal-level Cross-Functional Team}

A holistic approach to a NPD process covering several functions such as marketing, R\&D, design, supply chain, sales and manufacturing is key to success of both general NPD (Cooper, 2008) and sustainable design implementation (de Medeiros et al., 2014; Maletic et al., 2014, Charnley et al., 2011). In a real world though, the front-end is inclined to be further divided into minute stages, with 
different teams working at different stages instead of being cross-functional all through the process.

A) Sustainability officer involvement: Although indirect, a close involvement of the official decision makers in the process is desired. Currently in high SML cases (A and E) voluntary sustainability champions deliver the sustainability issues from the sustainability officers to the NPD team members.

B) Equal level engagement: Greater decision power for the marketing functions was observed in both the high and low SML cases. This is flagged to undermine the integrity of sustainable design practice.

"Usually the first stage is the marketer's job. Once they come up with the product concept, then designers begin to join." (Case D)

\section{Discussion}

This paper aims to increase understanding of the enabling factors for sustainable design implementation within the FMCG sector, with a focus on the front-end of the new product development (NPD) process. The roles and relative importance of the factors were investigated within varying case contexts and sustainability maturity levels, which allowed triangulation of diverse insights across multiple perspectives. This section discusses the categorisation of 11 factors and their sub-factors and attempts to explain their interrelationship through a framework.

\subsection{1 factors under three categories: Integrity, instrumentality and Externality}

The synthesis of findings resulted in clustering the identified 11 factors into three groups: Integrity, Instrumentality and Externality. While the existing factors are often categorised under practical themes such as management, collaboration, knowledge, we present a new type of grouping according to their intrinsic value to provide food for thought for researchers and industry practitioners. The value-laden approach responds well to the intrinsic, moral nature of sustainability, and helps the practitioners reflect the authenticity of their intention.

\subsubsection{Integrity}

The integrity group (Table 4) serves the overarching themes of sustainability penetration at the organisational, strategic and individual levels. This category includes five factors ranging from Balanced Focus on Growth and Consumer Insights, Firm and Knowledgeable Senior Leadership, Coherent Sustainability Vision, to Supportive Corporate Culture to Motivated, Satisfied and Ambitious Individuals. Above all the factors, this group of factors underpin the overall direction of a company, and their impact encompasses the company's sustainability practices deeply influencing the NPD. Thus they ought to precede other factors.

In the best practice case, these factors organically iterate with each other exchanging influences leading 
the company towards the higher maturity level. They are deeply connected to the underlying attitude of the business. Whereas all other factors can be suggested as success factors that could accelerate the success of product or project, the absence of this group can be fatal that hinder a company from achieving genuine sustainability of their practices.

Table 4. Integrity factors group and the sub-factors for sustainable design at the front-end of NPD

\begin{tabular}{|c|c|}
\hline INTEGRITY & Sub-factors \\
\hline \multirow{6}{*}{$\begin{array}{l}\text { 1. Balanced focus on growth } \\
\text { and consumer insights }\end{array}$} & a) Careful balance of Triple Bottom Line \\
\hline & b) Balanced reliance on consumer insight \\
\hline & c) Equal sustainability emphasis in brand portfolio \\
\hline & d) Marketing dominance avoidance \\
\hline & e) Economy of scale flexibility \\
\hline & f) Speed constraint flexibility \\
\hline \multirow{3}{*}{$\begin{array}{l}\text { 2. Firm and knowledgeable } \\
\text { Senior Leadership }\end{array}$} & a) Firm sustainability leadership \\
\hline & b) Familiarity with sustainability principles \\
\hline & c) Rewarding individuals for sustainability achievement \\
\hline \multirow{2}{*}{$\begin{array}{l}\text { 3. Coherent Sustainability } \\
\text { Vision }\end{array}$} & a) Alignment with company's general vision \\
\hline & b) Disseminated throughout company philosophy and daily activities \\
\hline \multirow[t]{6}{*}{ 4. Supportive corporate culture } & a) Transparency \\
\hline & b) Legacy \\
\hline & c) Behaviour \\
\hline & d) Belief \\
\hline & e) Structure \\
\hline & f) Citizenship \\
\hline \multirow{3}{*}{$\begin{array}{l}\text { 5. Motivated, Satisfied and } \\
\text { Ambitious Individuals }\end{array}$} & a) Motivation based on the company's past sustainability practice \\
\hline & b) Satisfaction about company’s present sustainability practice \\
\hline & c) Ambition about the company's future sustainability practice \\
\hline
\end{tabular}

Notably, balanced focus on consumer insights is categorised under the Integrity Group, not Externality. This is because the decision on the level of reflecting consumer insights is made entirely internally.

\subsubsection{Instrumentality}

The instrumentality group (Table 5) is about the factors affecting the operational side of the sustainable design implementation in the front-end of NPD. Five factors and their accompanying sub-factors are determined to affect the operation of specific design activities during the NPD. These factors could exert more direct influence on success of individual NPD outcomes than other factors, as they meet the practical needs and feed into each other during the process of NPD. It is difficult to argue they are only applicable at the front-end stages, Instead, their impact has to be affective from the front-end. This group includes factors of Healthy and multi-channel Internal Communication, Clear agreement on the terminology, Project-Level Sustainability Champion, Timely introduction of Customised Sustainability Tools and Equal-level Cross-Functional Team. 
Table 5 Instrumentality factors group and the sub-factors for sustainable design at the front-end of NPD

\begin{tabular}{|c|c|}
\hline Instrumentality & Sub-factors \\
\hline \multirow{2}{*}{$\begin{array}{l}\text { 6. Healthy and multi-channel } \\
\text { Internal Communication }\end{array}$} & a) Healthy interpersonal relationship \\
\hline & b) Variety of channels \\
\hline \multirow{2}{*}{$\begin{array}{l}\text { 7. Clear agreement on the } \\
\text { terminology }\end{array}$} & a) Agreed definition on sustainability terminology \\
\hline & b) Sense of sharing the same goal \\
\hline \multirow{2}{*}{$\begin{array}{l}\text { 8. Project-Level Sustainability } \\
\text { Champion }\end{array}$} & a) Official vs. voluntary \\
\hline & b) Project level involvement \\
\hline \multirow{2}{*}{$\begin{array}{l}\text { 9. Timely introduction of } \\
\text { Customised Sustainability } \\
\text { Tools }\end{array}$} & a) Customisation for company context \\
\hline & b) Timely introduction \\
\hline \multirow{2}{*}{$\begin{array}{l}\text { 10. Equal level cross-functional } \\
\text { team }\end{array}$} & a) Sustainability officer involvement \\
\hline & b) Equal level engagement \\
\hline
\end{tabular}

\subsubsection{Externality}

In this research, externality group (Table 6) includes only one factor and two sub-factors: Maturity of external contexts: consumer, market and infrastructure. Due to the sector's inseparable relationship with consumers, in case of low maturity level of the external contexts, the factor could discourage the implementation of sustainable design from the beginning, even if other factors are in place. However, it is arguable whether it is absolutely out of control. The high SML cases bravely embraced as a precondition to overcome even in the adverse conditions. We would argue that they are specific within the FMCG context but the expanded applicability could be considered in the further research. 
Table 6 Externality factors group and the sub-factors for sustainable design at the front-end of NPD

\begin{tabular}{ll}
\hline Externality & Sub-factors \\
\hline $\begin{array}{l}\text { 11. Maturity of external } \\
\text { contexts }\end{array}$ & a) Maturity of consumer / market \\
\hline
\end{tabular}

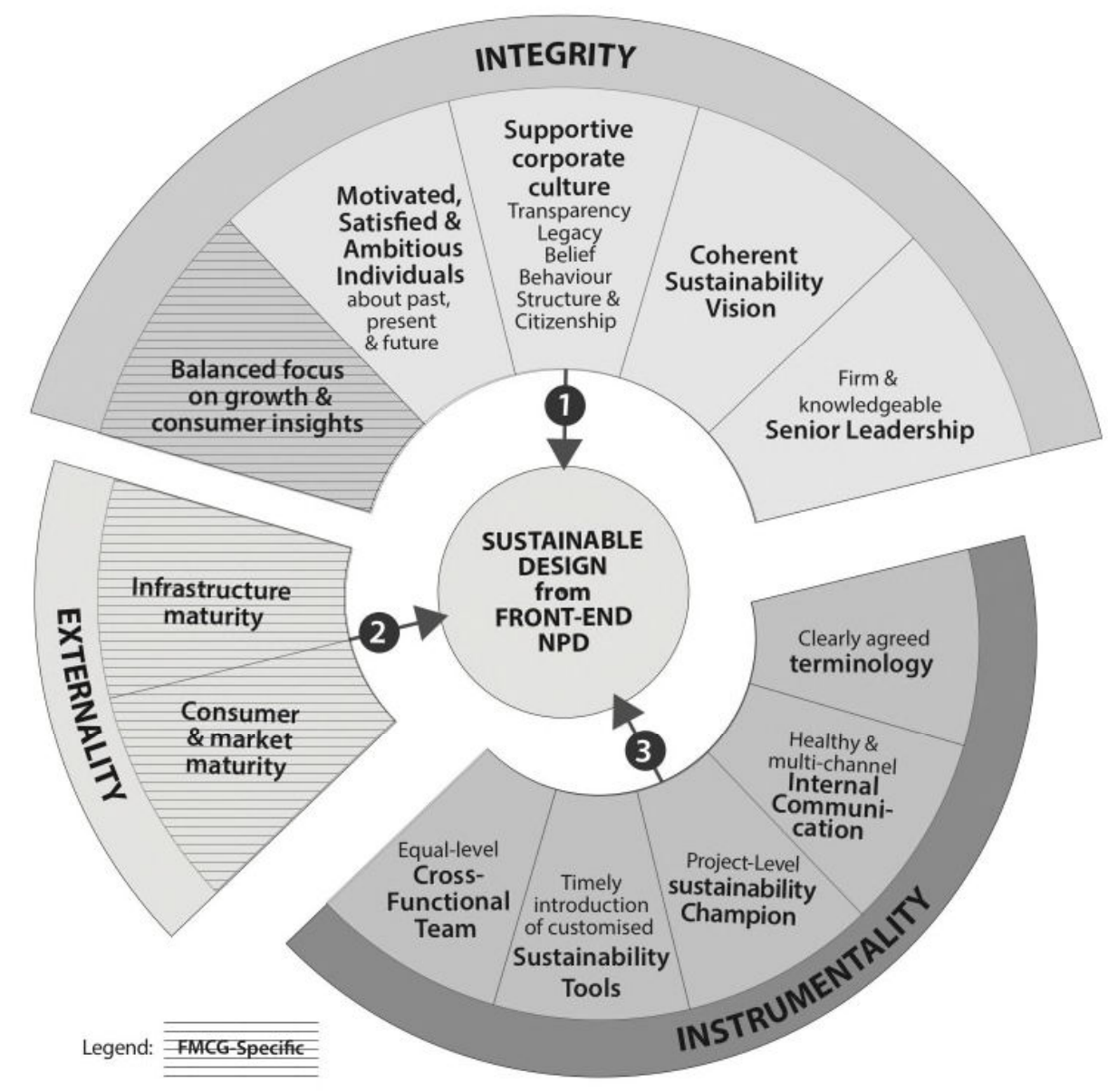

Figure 5.1 Framework of the interrelationships of enabling factors for sustainable design (SD) implementation in the frontend of NPD process within the FMCG sector 


\subsection{Framework of three factor groups: Integrity, instrumentality and externality}

The factors and their interrelationship are illustrated as a framework (Fig. 1) that emerged during the synthesis of the empirical findings. The retrospective development of a framework is unlike some other studies that explicitly render a conceptual framework beforehand and test through collecting data (e.g. Verhulst, 2012). The implication from the general null hypothesis contained in the research method would be that the weight of each factor is equal, and that the factors influencing the implementation process do it independently at an even level of importance, until proven otherwise. The synthesis of factor analysis has revealed that the individual factors do not stand-alone but interplay within and among the groups.

The different sizes and

$$
\text { ** Please insert Fig } 5.1 \text { here. }
$$

indicate the weights

groups of factors. the numbers of each group and the order among the Model of Ecodesign Integration (McAloone and Evans, 1999) that describes three stage of the organisational changes of 1) initial/sustained motivation, 2) communication/information flow, and 3) whole-life thinking provided the basis for the framework that the current research supports, although the focus of this model to describe the common sequence of events is based on the electronic/ electrical industry context.

Three factor groups within the framework closely interplay either as the sustainable design prerequisite factors (integrity) or as direct SD operational factors (instrumentality) or a context (externality).

Some factors in the first group of integrity may appear more relevant to the organisational level change management factors than sustainable design. However, we would like to emphasise their specific role as the conditions that must precede to pave the process to an introduction to sustainable design to their products. Often a company's sustainability deeds are judged as a thin fine line of green washing or a genuine practice, and the product design cannot help but reflect the integrity of the company. Without the integrity, it is difficult to achieve genuinely sustainable design. As such the direct, constant interactions with consumers through their purchase decision and usages amplify the importance of integrity factors group to the FMCG factor.

The externality factor group specifically reflects the FMCG characters of being consumer-driven.

Then it is followed by instrumentality factors that support sustainable design implementation activities at the product level.

The framework provides an easy-to-capture panoptic explanation of the phenomenon of sustainable design in the FMCG at a glance. This is particularly beneficial for non-academic audience, such as practicing FMCG designers, sustainability managers and FMCG management in deepening their understanding of the sequence and relative importance of the factors. Further, this would assist the 
practitioners in diagnosing their readiness level within the complex NPD process by checking the factors one by one.

\subsection{The higher the sustainability maturity level, the more positive evidence}

The quantitative questionnaire answers from each case was assessed under the categories of negative, positive, neutral or $n / a$ and illustrated in a graph (Figure 2). The cases are arranged in the order of the Sustainability Maturity Level: highest on the left high to the lowest in the right.

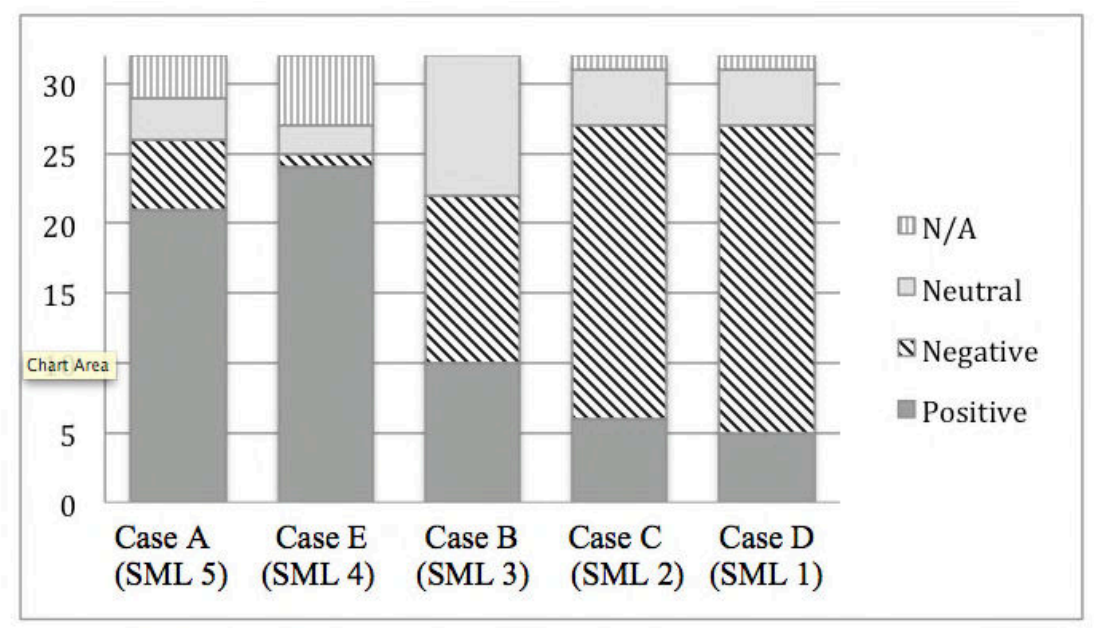

Figure 2 Tendency of evidence in five case companies at varying sustainability maturity levels

Figure 2 reveals the tendency of data categories from positive to negative dominance, from high to low SML cases [i.e. from left (dark grey: positive) to right (slashes: negative) via light grey (neutral)] is being presented. The dark grey bars (positive) diminish from left to right, and are gradually taken over by the slash bars (negative).

Prior to the empirical analysis, we assumed that the presence of the factors would be in a make or break fashion. In other words, the highest SML case would have it all, and the lowest with none. But the analysis shows rather a gradual changes of positive and negative evidence with a considerable amount of neutral or $\mathrm{n} / \mathrm{a}$ evidence across the cases. This reflects the real-world situation that even the most mature company has a room to improve.

Meanwhile, the light grey bar (neutral) dominates approximately $1 / 3$ of answers in case $\mathrm{B}$, and relatively larger horizontal bars (N/A: no applicable data) appear in the two highest cases (A and E). This is particularly noticeable as the horizontal bars (i.e. no applicable data) are concentrated in the FMCG factors group, which is due to a certain data extraction approach. For the challenge questions, the mid-to-low cases (case B, C, D) provided certain answers (e.g. high speed constraint, lack of alternative materials), while the high ones did chose the same items as challenges resulting no tangible data on this issue. These contrasting results can be explained by the difference in the companies' overall attitude and flexibility towards sustainability practice. 


\section{Conclusions}

This research contributes to the body of knowledge by shedding a light on four aspects: 1) crossdisciplinary insights by fusing the front-end of NPD factors and the sustainability implementation factors, 2) sustainable design factors in the FMCG context, 3) the correlation between the factors and the level of sustainability maturity of a company, and 4) the development of a framework.

First, the research investigated the sustainable design implementation factors from the front-end of NPD perspective. An extensive cross-disciplinary literature review on the challenges and drivers for sustainable design implementation and the general challenges for the front-end of an NPD process allowed new insights from both disciplines into the factors enabling an early adoption of sustainable design at the beginning of the NPD. The literature review revealed four common factors across the two research fields, and four other factors were controversial between two disciplines. Subsequently, the findings were framed in an in-depth questionnaire and for empirical data collection in five FMCG case companies. The cross-case analysis of empirical data refined the existing factors with a total of 32 newly added sub-factors. Notably, most of the factors except for one (i.e. sustainability tools) must be effective from the front-end of the NPD, but not only at the front-end. Rather than being considered at the beginning and slowing fizzle away, the emphasis on the factors has to be maintained throughout the entire NPD process.

Second, the qualitative analysis revealed two FMCG-specific factors (i.e. balanced focus on growth, maturity of external contexts) that are preconditions for a sustainable design uptake from the beginning. For former belongs to the integrity group and the latter belongs the externality group. Whereas these two factors were not detected outside FMCG, the rest of the factors remain rather generally applicable across different manufacturing sectors. Along with integrity factors, which are highly sociopsychological (i.e. supportive corporate culture, motivated, satisfied and ambitious individuals and coherent sustainability vision), the FMCG specific factors are recognized to cause a powerful, widespread impact on sustainable design implementation when preceding the instrumental (technical) factors. Moreover, the philosophical stance of a company, which can be seen in the way they define the ultimate business purpose and how they prioritise growth over other concerns affects the difference in their sustainability maturity levels.

Third, the quantitative data analysis of the survey results and the distribution of positive, negative, neutral or n/a data across the varying sustainability maturity levels (SMLs) of five sample case provided an insight into the correlation between the supportive evidence and the maturity. A clear pattern was that the more mature the case, the more positive evidence they had. In other words, in the maturer companies the factors play stronger roles, and can be found more often than in less mature companies. The medium SML case (Case B) had the evenest distribution of positive, negative and neutral evidence. However this did not mean that the highest SML case (Case A) has the highest number of positive evidence but the second highest case did (Case E). The commitment and 
accumulation of a long-term sustainability vision and strategy within a company, rather than the presence or absence of single factors appears to play a pivotal role in the sustainable design implementation.

Finally, the research outcomes are synthesised into a framework (Fig 1) that explains the interplay of the factors that influence the sustainable design implementation at the front-end of NPD in the FMCG context. While there are many academics claimed to have illustrated the phenomenon in a framework format, only a few succeeded to meet the definition of a framework by Naumann (1986). The proposed framework is designed to satisfy what readers would expect from a framework: to understand the conceptual systems consist of multiple concepts with many interrelated propositions (Meredith, 1993) by explicating the intertwined nature of the factors using a graphical interpretation. We anticipate that the framework will contribute to the body of knowledge, as well as to assist the managers and designers of the FMCG sector to diagnose their status quo with the sustainable design implementation and the steps to take in order to progress towards more sustainable practice.

This research poses a number of limitations, which would lead to the further research opportunities. First, from a strictly positivistic stance, the relatively small sample size of the research, as well as the concentration of the business category in the personal care product manufacturing cannot represent the entire FMCG industry. However, the in-depth investigation into each case using triangulated data analysis justifies the validity of the research. The focus on the personal care product was deliberately designed in order to control the design and NPD conditions. In addition, the distributed selection of the companies throughout varying sustainability maturity levels would justify the absolute number of the cases. A further research into a larger number of FMCG, or even cross-sectorial approach would verify the findings with higher generalisability and richer insight into wider implications.

Second, the research relies on the interviewees' honesty. The data would have been different if participation into the NPD process was allowed so that we could observe the actual conversations, the behaviours and the interactions among different functions and positions involved in the NPD. This also would allow collecting data from the external designers. A longitudinal research can be proposed to test and validate the identified factors and sub-factors over the entire NPD process. This would provide further information on how subsequent stages of NPD would affect the implementation.

Third, the framework was generated in the retrospective lacking the due validation step. A further empirical study would help test the framework in the real-world situation.

\section{Acknowledgements}

This work was partly supported by the Hammond Trust, British Council, Manchester, UK, 2014. 


\section{Reference}

Baumann, H., Boons, F., and Bragd, A. 2002. Mapping the Green Product Development Field, Engineering, Policy and Business Perspectives. Journal of Cleaner production. 10: 409-425.

Bhamra, T. A. 2004. Ecodesign: the search for new strategies in product development. Journal of Engineering Manufacture. 218: Part B.

Bocken, N. Farracho, M. Bosworth, R. and Kemp. R. 2014. The Front-End of Eco-Innovation for EcoInnovative Small and Medium Sized Companies. Journal of Engineering and Technology Management. 31: 43-57.

Boks, C. 2006. The Soft Side of Ecodesign. Journal of Cleaner Production. 14: 1346-1356.

Charnley, F., Lemon, M. and Evans, S. 2011. Exploring the Process of Whole System Design. Design Studies. 32: $156-179$.

Cooper, R.G. and Kleinschmidt, E.J. 1986. An Investigation into the New Product Process: Steps, Deficiencies, and Impact. Journal of Product Innovation Management. 3:71-85.

Cooper, R.G. 1988. Predevelopment Activities Determine New Product Success. Industrial Marketing Management. 17: 237-247.

Creswell, J.W. (2003), Research design: Qualitative, Quantitative, and Mixed Methods Approaches, Thousand Oaks: Sage.

Dekoninck, E.A., Domingo, L., O'Hare, J.A., Pigosso, D.C., Reyes, T. and Troussier, N., 2016. Defining the challenges for ecodesign implementation in companies: Development and consolidation of a framework. Journal of Cleaner Production, 135, pp.410-425.

De los Rios, I.C. and Charnley, F.J., 2017. Skills and capabilities for a sustainable and circular economy: The changing role of design. Journal of Cleaner Production, 160, pp.109-122.

De Medeiro, J.F., Ribeiro, J.L.D., and Cortimiglia, M.N. 2014. Success factors for environmentally sustainable product innovation: a systematic literature review. Journal of Cleaner Production. 65: 76-86.

Deshpandé, R., and Webster, Jr. F.E. 1989. Organizational and Marketing: Defining the Research Agenda, Journal of Marketing. 53: 3-15.

Deutz, P., McGuire, M. and Neighbour, G. 2013. Eco-Design Practice in the Context of a Structured Design Process: An Interdisciplinary Empirical Study of UK Manufacturers. Journal of Cleaner Production. 29:117128.

Diegel, O., Singamneni, S., Reay, S. and Withell, A., 2010. Tools for sustainable product design: additive manufacturing.

Dwyer, L. and Mellor, R. 1991. Organizational Environment, New Product Process Activities, and Project Outcomes. Journal of Product Innovation Management. 8(1): 39-48.

ECO2-IRN.1995. "Defining Eco-Design," presented at Workshop: Ecologically \& Economically Sound Design \& Manufacture - Interdisciplinary Research Network, Forum \#3. Manchester: Manchester Metropolitan University.

Ellen MacArthur Foundation. (2013). Towards the circular economy Vol. 2: Opportunities for the consumer goods sector. Available from: http://www.ellenmacarthurfoundation.org. [Accessed: 07 April 2016] 
Felekoglu, B., and Moultrie, J. 2014. Top Management Involvement in New Product Development: A Review and Synthesis. Journal of Product Innovation Management. 31(1):159-175.

Glavic, P. and Lukman, R. 2007. Review of Sustainability Terms and Their Definitions. Journal of Cleaner Production. 15: 1875-1885.

Goffin, K. 2012. Sustainability and new Product Development, in Cranfield on Corporate Sustainability. ed. Grayson, D. and Exeter, N. 105-118. Sheffield: Greenleaf.

Hallstedt, S., Ny, H., Robert, K-H. and Broman, G. 2010. An Approach to Assessing Sustainability Integration in Strategic Decision Systems for Product Development. Journal of Cleaner Production. 18: 703-712.

Hawken, P., Lovins, A. B., and Lovins, L. H. 2013. Natural capitalism: The next industrial revolution. London: Routledge.

Herriott, R. E., and Firestone, W. A. (1983), Multisite qualitative policy research: Optimizing description and generalizability, Educational researcher, 14-19.

Johansson, G. 2002. Success Factors for Integration of Ecodesign in Product Development: A Review of State of the Art. Environmental Management and Health. 13(1): 98-107.

Karlsson, R. and Luttropp, C. 2006. EcoDesign: What's Happening? An Overview of the Subject Area of EcoDesign and of the Papers in This Special Issue. Journal of Cleaner Production. 14: 1291-1298

Khurana, A. and Rosenthal, S.R.1998. Towards Holistic "Front Ends" in New Product Development. Journal of Product Innovation Management. 15:57-74.

Kim, J. and Wilemon, D. 2002. Focusing the Fuzzy Front-End in New Product Development. R\&D Management. 34(4): 269-279.

Koen, P., Ajamian, G., Burkart, R., Clamen, A., Davidson, J., D’Amore, R., Elkins, C., Herald, K., Incorvia, M., Johnson, A., Karol, R., Seibert, R., Slavejkov, A. and Wagner, K. 2001. Providing Clarity and a Common Language to the "Fuzzy Front End". Research Technology Management. 44(2): 46-55.

Keoleian, G.A. and Menerey, D.1994. Sustainable Development by Design: Review of Life Cycle Design and Related Approaches. Air \& Waste. 44(May): 645-668.

Kollmuss, A., and Agyeman, J. 2002. Mind the gap: why do people act environmentally and what are the barriers to pro-environmental behavior? Environmental education research. 8(3): 239-260.

Kurk, F. and Eagan, P. 2008. The Value of Adding Design-For-The Environment to Pollution Prevention Assistance Options. Journal of Cleaner Production. 16: 722-726.

Langerak, F., Hultink, E. J. and Robben, H. S. J. 2004. The Role of Predevelopment Activities in the Relationship Between Market Orientation and Performance. R\&D Management. 34(3): 295-309.

Lee-Mortimer, A. and Short, T. 2009. The Product Development Process Roadblock that is Restricting the Wide Spread Adoption of Design for Sustainability. International Conference on Engineering Design. Stanford: 3:331-342.

Lenox, M. and Ehrenfeld, J. 1997. Organizing for Effective Environmental Design. Business Strategy and the Environment. 6: 187-196.

Luttropp, C. and Lagerstedt, J. 2006. EcoDesign and The Ten Golden Rules: Generic Advice for Merging Environmental Aspects into Product Development. Journal of Cleaner Production. 14: 1396-1408. 
Madge, P.1997. Ecological Design: A New Critique. Design Issues. 13(2):44-54.

Maletic, M., Maletic, D., Dahlgaard, J.J. and Dahlgaard-Park, S.M. 2014. Sustainability Exploration and Sustainability Exploitation: from a Literature Review towards a Conceptual Framework. Journal of Cleaner Production. 79:182-194.

McAloone, T.C., and Evans, S. (1999), Using Empirical Data to Build an Advisory Tool for Eco-Design, Ecodesign 99' Proceedings of First International Symposium on Environmentally Conscious Design and Inverse Manufacturing, Tokyo, 52-55.

McLellan, B.C. and Corder, G.D. 2013. Risk Reduction through Early Assessment and Integration of sustainability in Design in the Minerals Industry. Journal of Cleaner Production. 53: 37-46.

Meredith, J. (1993), Theory Building through Conceptual Methods, International Journal of Operations and Production Management, Vol. 13, No. 5, pp. 3-11

Mirvis, P., and Googins, B. 2006. Stages of corporate citizenship: A developmental framework. California Management Review. 48 (2): 104-126.

Moenaert, R.K., De Meyer, A., Souder, W.E. and Deschoolmeester, D. 1995. R\&D/Marketing Communication During the Fuzzy Front-End, IEEE Transaction on Enginering Management. 42(3): 243-258.

Moreno, M., De los Rios, C., Rowe, Z. and Charnley, F., 2016. A conceptual framework for circular design. Sustainability, 8(9), p.937.

Muñoz, I., Gazulla, C., Bala, A., Puig, R., and Fullana, P. 2009. LCA and ecodesign in the toy industry: case study of a teddy bear incorporating electric and electronic components. The International Journal of Life Cycle Assessment, 14(1), 64-72.

Murphy, S.A. and Kumar, V. 1997. The Front End of New Product Development: a Canadian Survey. R\&D Management. 27(1):5-15.

Naumann, J.D., 1986, November. The role of frameworks in MIS research. In Proceeding of the 1986 DSI National Meeting, Honolulu, Hawaii (pp. 569-571).

O'Hare, J.A. 2010. Eco-innovation tools for the early stages: an industry-based investigation of tool customisation and introduction. Doctoral thesis. University of Bath.

Onwuegbuzie, A. J., and Teddlie, C. (2003), A framework for analyzing data in mixed methods research. Handbook of mixed methods in social and behavioral research, 351-383.

Oxfam. 2014. Standing on the Sidelines: Why food and beverage companies must do more to tackle climate change. 186 Briefing paper.

Park, C. (2015) Influencing Factors For Sustainable Design Implementation In The Front-End Of New Product Development Process Within The Fast-Moving-Consumer-Goods Sector, Doctoral Thesis, Cranfield University Petala, E. Wever, R. Dutilh, C. Brezet, H. 2010. The Role of New Product Development Briefs in Implementing Sustainability: A Case Study. Journal of Engineering and Technology Management. 27: 172-182.

Pigosso, D.C.A., Rozenfeld, H., McAloone, T. 2013. Ecodesign Maturity Model: A Management Framework to Support Ecodesign Implementation into Manufacturing Companies. Journal of Cleaner Production. 59: 160173. 
Plouffe, S., Lanoie, P., Berneman, C. and Vernier, M-F. 2011. Economic Benefits Tied to Ecodesign. Journal of Cleaner Production. 19: 573-579.

Poole, S. and Simon, M. 1997. Technological Trends, Product Design and the Environment. Design Studies. 18(3): 237-248.

Pujari, D. 2006. Eco-innovation and new product development: understanding the influences on market performance. Technovation. 26(1): 76-85.

Riel, A., Neumann, M. and Tichkiewitch, S., 2013. Structuring the early fuzzy front-end to manage ideation for new product development. CIRP Annals-Manufacturing Technology, 62(1), pp.107-110.

Ritzen, S. and Beskow, C. 2002. Actions for Integrating Environmental Aspects into Product Development. The Journal of Sustainable Product Design. 1(2):91-102.

Robson, C. 2011. Real World Research. Chichester : Wiley.

Rossi, M., Germani, M. and Zamagni, A., 2016. Review of ecodesign methods and tools. Barriers and strategies for an effective implementation in industrial companies. Journal of Cleaner Production, 129, pp.361-373.

Sandstrom, G.O. and Tingstrom, J. 2008. Management of Radical Innovation and Environmental Challenges: Development of the DryQ Capacitor at ABB. European Journal of Innovation Management. 11(2): 182- 198.

Sherwin, C. 2000. Innovative Ecodesign: an exploratory and descriptive study of Industrial Design practice. Doctoral Thesis. Cranfield University.

Short, T., Lee-Mortimer, A., Luttropp, C. and Johansson, G. 2012. Manufacturing, Sustainability, Ecodesign and Risk: Lessons Learned from a Study of Swedish and English Companies. Journal of Cleaner Production. 37: 342-352.

Shuaib, M., Seevers, D., Zhang, X., Badurdeen, F., Rouch, K. E., and Jawahir, I. S. 2014. Product Sustainability Index (ProdSI). Journal of Industrial Ecology, 18(4): 491-507.

Simon, M., Evans, S., McAloone, T., Sweatman, A., Bhamra, T. and Poole, S. 1997. Ecodesign Navigator, Bedfordshire: Cranfield University.

Srinivasan, S. and Lu, W.F., 2014. Development of a supporting tool for sustainable FMCG packaging designs. Procedia CIRP, 15, pp.395-400.

Tien, S-W., Chung, Y-C. and Tsai, C-H. 2005. An empirical study on the correlation between environmental design implementation and business competitive advantages in Taiwan's industries. Technovation. 25(7): 783794.

Tierney, R.J. 2002. Green by Design: Factor Ten Goals at Pratt \& Whitney. Corporate Environmental Strategy. 9(1): 52-61.

Van der Vorst, J. G., Tromp, S. O., \& Zee, D. J. V. D. 2009. Simulation modelling for food supply chain redesign; integrated decision making on product quality, sustainability and logistics. International Journal of Production Research, 47(23), 6611-6631.

Verhulst, E. 2012. The human Side of sustainable design implementation from the perspective of change management. Doctoral thesis. Universiteit Antwerpen. 
Verhulst, E., and Boks, C. 2014. Employee empowerment for sustainable design. The Journal of Corporate Citizenship, (55), 73

Yin, R.K. (2003), Case Study Research: Design and Methods: Applied Social Research Methods, Volume 5, 3rd Ed. London: Sage. 
Appendix 1. $1^{\text {st }}$ Questionnaire example

\section{SECTION 1: COMMON NPD SUCCESS FACTORS}

- SECTION 1 AIMS TO CONFIRM COMMON SUCCESS FACTORS THAT ATTRIBUTE TO SUCCESSFUL NPD.

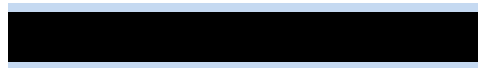

1.A.1 PLEASE INDICATE THE IMPORTANCE OF CONSUMER INVOLVEMENT IN ACHIEVING SUCCESS WITHIN THE FOLLOWING FRONT-END NPD ACTIVITIES:

SCALE: 1 = NOT IMPORTANT AT ALL, 3 = NEUTRAL, 5 = VERY IMPORTANT
(A) Slage 0
: Ideageneration
$\begin{array}{lllll}1 & 2 & 3 & 4 & 5\end{array}$
:
$\begin{array}{lllll}1 & 2 & 3 & 4 & 5\end{array}$
(B-1) : Preliminary assessment of market
$\begin{array}{lllll}1 & 2 & 3 & 4 & 5\end{array}$
(B-2) Sooping
:Preliminary assessment of technology
$\begin{array}{lllll}1 & 2 & 3 & 4 & 5\end{array}$
(G1) Stage2 :Def neproduct concepts
(G2) Business Case :Def nedesign requirements \& specif cations
$\begin{array}{lllll}1 & 2 & 3 & 4 & 5\end{array}$
(D-1) Building
:Evaluateoutcomes
$\begin{array}{lllll}1 & 2 & 3 & 4 & 5 \\ 1 & 2 & 3 & 4 & 5\end{array}$

1.A.2 PLEASE INDICATE THE FREQUENCY OF CONSUMER INVOLVEMENT WITHIN THE FOLLOWING FRONT-END NPD ACTIVITIES:

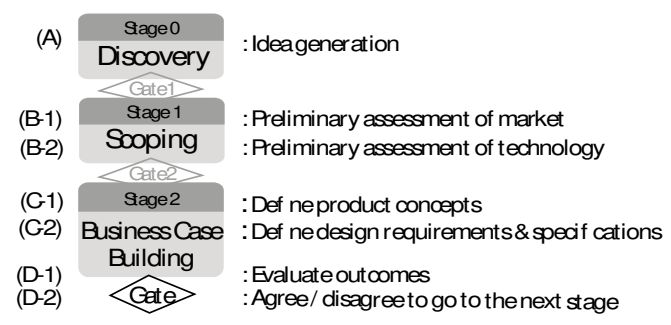

SCALE: 1 = NEVER, $3=$ SOMETIMES, 5 = ALWAYS

1.A.3 PLEASE INDICATE THE EFFECTIVENESS OF CONSUMER INVOLVEMENT WITHIN THE FOLLOWING FRONT-END NPD ACTIVITIES:

Scale: 1 = NOT EFECTIVE AT ALL, 3 = NEUTRAL, 5 = VERY EFFECTIVE
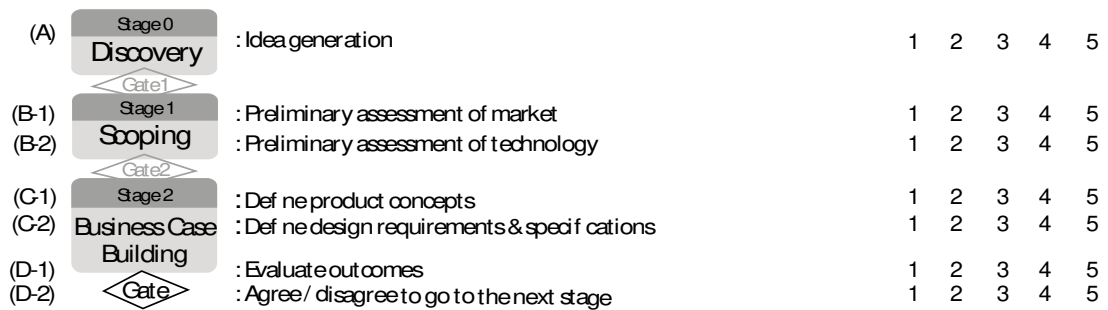
1.A.4 PLEASE INDICATE THE FREQUENCY OF CONSUMER INVOLVEMENT WITHIN THE FRONT-END NPD ACTIVITIES (Write a number in the square):

SCALE: 1 = NEVER, 3 = SOMETIMES, 5 = ALWAYS

(A)End Users

(B) Purchasers

(C) Retailers

(D) Other (Please specify:

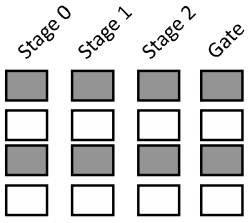

1.A.5 PLEASE INDICATE THE VALUE OF CONSUMER INVOLEMENT IN ACHIEVING SUCCESS IN YOUR NPD ACTIVITIES (Write a number in the square)

Scale: $1=$ NO, $3=$ NEUTRAL, $5=\mathrm{HIGH} \quad$ FREQUENCY
(A) Identifying real consumer needs \& wants
(B) Reducing NPD time
(C) Developing healthy pipeline with consumers
(D) Reducing market uncertainty
(E) Other (Please specify:

) 12345

1.A.6 HOW WOULD YOU DEFINE SUCCESS IN RELATION TO CONSUMER INVOLVEMENT?

EXMAPLE? 
Appendix 2. 2n ${ }^{\text {nd }}$ Questionnaire example

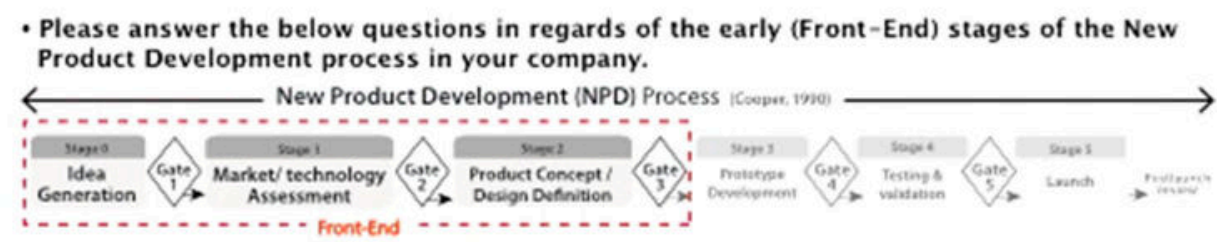

E.2. Is there an agreed wording to use (from E.1) in your company?

E.2-1. If YES, which one is it?

Yes

No

E.3. How important to use an agreed wording?

E.4. Why (or why not)?

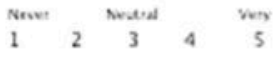

\section{F. Sustainability Champion}

- Sustainability champion (environmental coordinator/advisor).

A person in charge of the sustainability consideration in design, often from middle manager level

F.1. How important is to have a sustainability champion in the early stage of the NPD in your company?

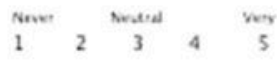

F.2. Is there a such person in your company?

F.2-1. If YES, how often does this person come in the early stage?

Yes

No

F.2-2. If YES, How effective is it?

F.3. If NO, is there a need for one?

F.3.-1.Why (or why not??

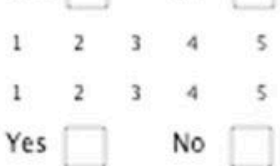

\section{Sustainability Tools}

C.1. How important is to use a sustainability tool(s) in the early stage of the NPD in your company?

G.2. Are any sustainability tool(s) used in your company?

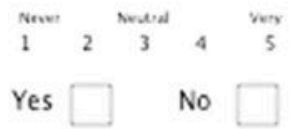

C.2-1. If YES, please specify (including company's own):

C.2-2. If YES, How often are they used?

C.2-3. If YES, How effective are they?

C.3. If NO, is there a need for one?

C.3-1.Why (or why not)?

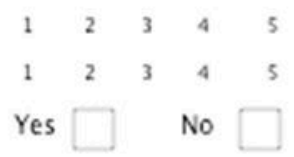




\section{H. Sustainability Vision}

H.1. What is your company's vision?

H.2. What is your company's sustainability vision?

H.3. How important is to have sustainability within your company vision? $\begin{array}{ccccc}\text { Never } & \text { Neutral } & \text { Very } \\ 1 & 2 & 3 & 4 & 5\end{array}$ H.4. Why (or why not)?

\section{Corporate Culture of Sustainability}

I.1. Do you think there is culture of sustainability in your company? Yes $\square$ No

I.2. How important is sustainability transparency in your corporate culture? Never Neutral very Any example?

1.4. How important is sustainability innovation in your corporate culture? Any example? Any example?

I.6. How important is sustainability belief in your corporate culture? Any example?

I.7. How important is sustainability citizenship in your corporate culture? Any example?

I.8. How structured is sustainability practice in your corporate culture? Any example? 